\title{
Von Willebrand disease as a significant risk factor for hemorrhage after cervical loop electrosurgical excision
}

\author{
Anita Ungure $^{1 *}$, Jana Žodžika ${ }^{2,3}$, Diāna Kuṇicina ${ }^{2,3}$, Nellija Lietuviete ${ }^{2,3}$, Dace Rezeberga ${ }^{2,3}$
}

\author{
${ }^{1}$ Department of Medicine, Riga Stradiņš University, Riga, Latvia \\ ${ }^{2}$ Department of Gynecology and Obstetrics, Riga Stradinšs University, Riga, Latvia \\ ${ }^{3}$ Gynecological Clinic, Riga East Clinical University Hospital, Riga, Latvia
}

Received: 14 June 2018

Accepted: 18 June 2018

\section{*Correspondence:}

Dr. Anita Ungure,

E-mail: anita.ungure@gmail.com

Copyright: (C) the author(s), publisher and licensee Medip Academy. This is an open-access article distributed under the terms of the Creative Commons Attribution Non-Commercial License, which permits unrestricted non-commercial use, distribution, and reproduction in any medium, provided the original work is properly cited.

\begin{abstract}
Loop electrosurgical excision procedure (LEEP) is the first-line treatment for cervical intraepithelial neoplasia (CIN). It is effective, easy to perform and relatively safe for the patient. However, 1-2\% of patients experience complications such as hemorrhage and infection, which usually are effectively treated using cauterization and antibiotics. We are presenting a case of repeated cervical and vaginal hemorrhage after the cervical LEEP for a patient without previous medical history of severe bleeding or detected bleeding disorders. A generally healthy 38 -year-old female underwent planned LEEP of cervix because of CIN II-III. Procedure was successful. Afterwards she was admitted to the Emergency department several times because of recurrent vaginal and cervical bleeding. She received suturing and coagulation of the cervix and vaginal wall combined with desmopressin and tranexamic acid therapy. Because of suspected bleeding disorder hematologist was invited. Laboratory analysis showed positive results for von Willebrand disease. After VIII/von Willebran factor concentrate treatment bleeding was stopped completely. Before any surgical interventions it is important to take a detailed medical history. If atypical, recurrent and/or severe secondary hemorrhage after the surgical manipulations occur, coagulation disorders should be excluded.
\end{abstract}

Keywords: Gynaecology, Loop excision of cervix, Von Willebrand disease

\section{INTRODUCTION}

Loop electrosurgical excision procedure (LEEP) is the first-line treatment for a high-grade cervical intraepithelial neoplasia (CIN). The effectiveness of that type of treatment is significantly high (recurrence of CIN $5.3 \%){ }^{1}$

Although LEEP is relatively safe for the patient complications tend to happen. Up to $1-2 \%$ of patients experience short-term complications such as primary bleeding or secondary hemorrhage due to infection. Data from systematic reviews show that major bleeding occurs in $0.2 \%$ and minor bleeding in $0.4 \%$ of cases after undergoing the LEEP. $^{2,3}$ Usually complications are effectively treated using electrocoagulation, antibiotics, but in the most severe cases cervical sutures can be placed. ${ }^{4}$

We would like to present a clinical case of recurrent cervical hemorrhage after the cervical LEEP for a patient without previous medical history of bleeding disorders.

\section{CASE REPORT}

A generally healthy 38-year-old female was admitted to the Day Stay clinic of the Gynaecological department for a planned cervical loop electrosurgical excision procedure (LEEP) because of previously detected CIN IIIII in a colposcopic-directed biopsy. No co-existing 
diseases were recognized. From reproductive history: menarche at 12 years; ovarian cyst torsion followed with laparoscopic ovarian cystectomy in 2003; three vaginal uncomplicated deliveries (2007, 2009, 2015); missed abortion in 2006; medical abortion in 2013; all events without major bleeding complications.

During the LEEP a suspicious area on the right lateral wall of vagina was observed and excisional biopsy was done with the following coagulation. Patient was discharged in a good condition on the same day.

10 days after the LEEP patient presented to the Emergency department with complaints of severe vaginal bleeding with blood clots for 2 days. Intensive cervical bleeding was detected during per specula examination and cervical sutures were placed to stop the hemorrhage. 3 days later vaginal bleeding reoccurred. Examination with speculum revealed $1.5 \mathrm{~cm}$ long mucosal lesion on the right lateral wall of the vagina. Coagulation of the vaginal wall lesion site stopped hemorrhage. After that episode the patient was admitted twice to the Emergency department because of severe cervical and vaginal bleeding. Cervical and vaginal wall electrocoagulation, suturing of the cervix and vaginal wall was done along with hemostatic sponge insertion, but those efforts were insufficient, and bleeding repeated. During admissions patient had received therapy with tranexamic acid 1000 $\mathrm{mg}$ per day $\mathrm{i} / \mathrm{v}$ for 6 days, ethamsylate $2 \mathrm{ml} \mathrm{i} / \mathrm{m}$, ciprofloxacin $500 \mathrm{mg}$ p/o for 7 days. Meanwhile mild anemia developed (hemoglobin $11.6 \mathrm{~g} / \mathrm{dL}$ (reference interval 12.0 - 14.0) and therefore oral iron replacement therapy was prescribed.

When the vaginal and cervical bleeding started again, abnormal coagulation analysis was detected. The most important indicator was elevated partial thromboplastin time (PTT), which reached 60.7 seconds (reference interval 28 - 40). Hematologist was invited to exclude a bleeding disorder. Analysis confirmed von Willebrand disease: von Willebrand factor (vWF:Ag) concentration was reduced to $25 \%$ (reference interval 50-160) and VIII factor (FVIII) concentration was reduced to $10 \%$ (reference interval 60 - 150), partial thromboplastin time remained elevated to 54.0 seconds $(28-40)$ and mild anemia with hemoglobin $11.8 \mathrm{~g} / \mathrm{dL}$ (reference interval 12.0-14.0) maintained. Immediate therapy of 18 micrograms (0.3 micrograms $/ \mathrm{kg}$ ) of desmopressin over 30 minutes was given i/v and analysis for PTT, vWD:Ag and FVIII were repeated within an hour. The bleeding was stopped. Patient was discharged with recommendations to use desmopressin for $\mathrm{s} / \mathrm{c}$ injections and tranexamic acid p/o, if bleeding reoccurs.

Within 7 days patient returned to Emergency department with complaints about severe vaginal bleeding, the patient had taken desmopressin injections and tranexamic acid, but she experienced side effects such as nausea and vomiting combined with dizziness and palpitations. After repeated consultation with hematologist therapy was changed to $1500 \mathrm{IU}$ (25 IU/kg) of VIII/von Willebrand factors concentrate $\mathrm{i} / \mathrm{v}$ every 8 hours until the hemorrhage was stopped completely. She also received tranexamic acid $500 \mathrm{mg} \mathrm{i} / \mathrm{v}$ twice per day for 6 days, ethamsylate 2 $\mathrm{mL} /$ day $\mathrm{i} / \mathrm{m}$ for 2 days and antibiotic treatment with metronidazole $100 \mathrm{mg}$ twice per day $\mathrm{i} / \mathrm{v}$ for 7 days and ceftriaxone $1 \mathrm{~g} /$ day $\mathrm{i} / \mathrm{v}$ for 7 days. The patient was discharged in a good condition with prescription of an oral contraception and tranexamic acid $0.5 \mathrm{mg} 3$ times per day $\mathrm{p} / \mathrm{o}$ during menstruations if needed.

In the follow-up visit within 4 months patient had no complaints, previous menstrual bleeding lasted for 5 days without a need to use tranexamic acid. Last 6 months menstrual cycles were regular with moderate bleeding and patient did not have to use tranexamic acid during menstruations. Post-treatment cytological test and highrisk HPV tests were negative. Patient had reviewed vaccination against human papilloma virus.

\section{DISCUSSION}

Most common symptoms among women with the von Willebrand disease (vWD) are heavy menstrual bleeding, bruising and epistaxis, but this patient did not point out any of them in the preoperative examination. ${ }^{5}$ Bleeding after minor surgery can occur in $80 \%$ of all vWD cases. 6 It is not typical to have a severe vaginal and cervical bleeding after the LEEP as a first presenting symptom of vWD.

Previous laparoscopic cystectomy and three deliveries in anamnesis without a notable blood loss led to delayed diagnosis. That means in every case with unexplained repeated hemorrhage after any minimally invasive gynecological procedures underlying bleeding disorder should be considered and evaluation of coagulation factors should be worked out.

Not only genetic heterogeneity, including ABO-blood group, but also physiological factors such as age, acutephase response and menstrual cycle affects von Willebrand factor levels and therefore the variability of signs and symptoms among patients with vWD could occur. ${ }^{7}$ It is still a priority to focus on the particular patient and evaluate the signs and symptoms of the disease. There is a strong evidence that diagnosis of this condition is demanded to be over-and underdetected because of clinical misperception of actual prevalence of vWD. Limitations in the current test procedures and overreliance on these incomplete test systems contributes inaccuracies in diagnostics of vWD. ${ }^{8}$

According to the evidence-based reports first-line treatment for vWD is desmopressin, but in this case, it was ineffective. This could be explained by variable response to desmopressin- as reported it could be ineffective for types $2 \mathrm{~B}, 2 \mathrm{~N}$ and type $3 \mathrm{vWD}$ and there is data which suggests that also type $1 \mathrm{vWD}$ could be unresponsive to this therapy. Number of factors play role 
in the response of desmopressin, including the genotype and phenotype of the disease. In this case the specific type of vWD was not analyzed.

For this patient the side effects could be induced either by desmopressin or tranexamic acid, however desmopressin is considered to be safe and side effects such as headache, tachycardia, tremor, abdominal pain and sweating are commonly considered as a consequence of rapid intravenous infusion., ${ }^{9,10}$ Tranexamic acid could possibly have caused mentioned adverse effects such as dizziness, nausea, diarrhea and abdominal pain. ${ }^{11,12}$

Commercially available recombinant von Willebrand factor-containing concentrates are treatment of choice for most patients with type 2 and type 3 with vWD. Infused together with recombinant factor VIII has shown high efficacy to stop the bleeding without significant side effects. Results of analysis for von Willebrand factor inhibitors were negative, so this therapy was considered safe. In this case it proved to be the most effective therapy method. ${ }^{13}$

For women with proven vWD treatment with combined oral contraceptives or levonorgestrel-releasing intrauterine device placement should be initiated. Antifibrinolytic treatment with tranexamic acid or aminocaproic acid should be added during menstruations to reduce the blood loss. ${ }^{14,15}$

Even when the patient does not have a significant medical history when repeated cervical and vaginal hemorrhage occurs it is important to estimate the possibility of an underlying disorder. Because of variable natural bleeding events during menstruations and childbirth underlying bleeding disorders among women with reproductive tract hemorrhage sometimes are inappropriately evaluated. Lack of applicable clinical tools to objectify abnormal reproductive tract bleeding and deficient awareness among clinicians increase amount of cases with underdiagnosed and suboptimal treatment for women with bleeding disorders. As the incidence of vWD in the general population is estimated to be $1 \%$, therefore it should be always excluded in women with abnormal vaginal bleeding. It is also recommended to exclude bleeding disorder before every invasive procedure by carefully examining patient's medical history about the menorrhagia since menarche; family history of a bleeding disorders; bilateral epistaxis $>10$ minutes; notable bruising without injury $>2 \mathrm{~cm}$; minor wound bleeding $>5$ minutes; bleeding of oral cavity or gastrointestinal tract without an obvious anatomic lesion; prolonged bleeding after dental extraction; unexpected post-surgical bleeding; hemorrhage from ovarian cysts or corpus luteum; hemorrhage that required blood transfusion; postpartum hemorrhage (especially delayed - after 24 hours); failure of response of conventional management of menorrhagia. ${ }^{16,17}$

\section{CONCLUSION}

This case study showed atypical first-time presentation for a woman with vWD. It implies that every woman with recurrent hemorrhage after the LEEP should be considered at risk and immediate actions should be taken. All women with unexplained heavy menstrual bleeding, postpartum or postsurgical hemorrhage or positive family history should be evaluated for coagulation disorders.

Updates in local guidelines are needed to identify risk factors for postoperative bleeding in gynecology for women with inherited bleeding disorders. To achieve that standardized screening tools like questionnaires should be used. That would help to predict increased risks for postsurgical hemorrhage and to prepare for procedures avoiding major complications.

\section{Funding: No funding sources \\ Conflict of interest: None declared}

Ethical approval: This study was approved by The Ethics Committee of Riga Stradiňš University.

\section{REFERENCES}

1. Santesso N, Mustafa RA, Wiercioch W, Kehar R, Gandhi S, Chen Y, et al. Systematic reviews and meta-analyses of benefits and harms of cryotherapy, LEEP, and cold knife conization to treat cervical intraepithelial neoplasia. Int $\mathbf{J}$ Gynecol Obstet. 2015;132(3):4-9.

2. Maleerat P, Chumworathayi B, Kietpeerakool C, Luanratanakorn S, Temtanakitpaisan A. Post-Loop Electrosurgical Excision Procedure Complications in Srinagarind Hospital. Asian Pac J Cancer. 2016;17:2211-5.

3. Sutthichon P, Kietpeerakool C. Perioperative complications of an outpatient loop electrosurgical excision procedure: A review of 857 consecutive cases. Asian Pacific J Cancer Prev. 2009;10(3):3514.

4. Shiraz A, Majmudar T. Colposcopy and cervical intraepithelial neoplasia. Obstet Gynaecol Reprod Med. 2017;27(6):177-83.

5. Disease VW. ACOG Committee Opinion: von Willebrand disease in women. Obstet Gynecol. 2013;122(6):1368-73.

6. Leebeek FWG, Eikenboom JCJ. Von Willebrand's Disease. N Engl J Med. 2016;375(21):2067-80.

7. Baronciani L, Goodeve A, Peyvandi F. Molecular diagnosis of von Willebrand disease. Haemophilia. 2017;23(2):188-97.

8. Favaloro EJ, Pasalic L, Curnow J. Laboratory tests used to help diagnose von Willebrand disease: an update. Pathology. 2016;48(4):303-18.

9. Walle J.V., Stockner M., Raes A., Norgaard J.P. Desmopressin 30 years in clinical use: a safety review. Curr Drug Sat. 2007;232-8 
10. Mannucci P, Bianchi A. Desmopressin (DDAVP) in the treatment of bleeding disorders. Treat Hemoph. 2012;(11):1-9.

11. Ng WC, Jerath A, Wasowicz M. Tranexamic acid: a clinical review. Anaesthesiol Intensive Ther. 2015;47(4):339-50.

12. Laffan M, Brown SA, Collins PW, Cumming AM, Hill FGH, Keeling D, et al. The diagnosis of von Willebrand disease: a guideline from the UK Haemophilia Centre Doctors' Organization. Haemophilia. 2004;10(3):199-217.

13. James P, Rydz N. Structure, Biology, and Genetics of von Willebrand Factor. In: Hoffman R, Benz EJ, Silberstein LE, eds. Hematology: Basic Principles and Practice. $7^{\text {th }}$ ed. Philadelphia, PA: Elsevier; 2018: 2051-2063

14. Demers C, Derzko C, David M, Douglas J. Gynaecological and Obstetric Management of Women With Inherited Bleeding Disorders. J Obstet Gynaecol Canada. 2018;40(2):e91-103.

15. Alikhan R. Treatment of patients with von Willebrand disease. J Blood Med. 2011;49.
16. James AH, Kouides PA, Abdul-Kadir R, Edlund M, Federici $\mathrm{AB}$, Halimeh $\mathrm{S}$, et al. Von Willebrand disease and other bleeding disorders in women: consensus on diagnosis and management from an international expert panel. Am J Obstet Gynecol. 2009;201(1):12.e1-e8.

17. Nichols WL, Hultin MB, James a H, MancoJohnson MJ, Montgomery RR, Ortel TL, et al. von Willebrand disease (VWD): evidence-based diagnosis and management guidelines, the National Heart, Lung, and Blood Institute (NHLBI) Expert Panel report (USA). Haemophilia. 2008;14(2):171232.

Cite this article as: Ungure A, Žodžika J, Kuṇicina D, Lietuviete N, Rezeberga D. Von Willebrand disease as a significant risk factor for hemorrhage after cervical loop electrosurgical excision. Int J Reprod Contracept Obstet Gynecol 2018;7:2926-29. 